\title{
Leveraging sap flow data in a catchment-scale hybrid model to improve soil moisture and transpiration estimates
}

\author{
Ralf Loritz ${ }^{1}$, Maoya Bassiouni ${ }^{2,3}$, Anke Hildebrandt ${ }^{4,5,6}$, Sibylle K. Hassler ${ }^{1,5}$, Erwin Zehe ${ }^{1}$
}

${ }^{1}$ Karlsruhe Institute of Technology (KIT), Institute of Water and River Basin Management - Hydrology, Karlsruhe, Germany

5 2Department of Crop Production Ecology, Swedish University of Agricultural Sciences, Uppsala, Sweden. ${ }^{3}$ Department of Environmental Science, Policy and Management, University of California, Berkeley, CA, USA

${ }^{4}$ Helmholtz Centre for Environmental Research - UFZ, Department Computational Hydrosystems, Leipzig, Germany

${ }^{5}$ Karlsruhe Institute of Technology (KIT), Institute of Meteorology and Climate Research - Atmospheric Trace Gases and Remote Sensing, Karlsruhe, Germany

$10{ }^{6}$ Friedrich Schiller University Jena, Institute of Geoscience, Jena, Germany

Correspondence to: Ralf Loritz (Ralf.Loritz@kit.edu)

\begin{abstract}
Sap flow encodes information about how plants regulate opening and closing of stomata in response to varying soil water supply and atmospheric water demand. This study leverages this valuable information with data-model integration and deep learning to estimate canopy conductance in a hybrid catchment-scale model for more accurate hydrological simulations. Using data from three consecutive growing seasons, we first highlight that integrating canopy conductance inferred from sap flow data in a hydrological model leads to more realistic soil moisture estimates than using the conventional Jarvis-Stewart equation, particularly during drought conditions. The applicability of this first approach is, however, limited to the period where sap flow data are available. To overcome this limitation, we subsequently train a deep learning network to predict catchmentaveraged sap velocities based on standard hourly meteorological data. These simulated velocities are then used to estimate canopy conductance, allowing simulations for periods without sap flow data. We show that the hybrid model, which uses the canopy conductance from the machine learning approach, matches soil moisture and transpiration equally well as model runs using observed sap flow data and has good potential for extrapolation beyond the study site. We conclude that such hybrid approaches open promising perspectives for more parsimonious process parametrizations by improving our ability to incorporate novel or untypical data sets into hydrological models.
\end{abstract}

\section{Introduction}

Globally, about 26 to $40 \%$ of the precipitation that falls on the continents is transpired by vegetation, making it one of the dominant fluxes of the terrestrial water cycle (Dingman, 2015). Seasonal variations in plant water use can thus significantly 30 affect the water balance of catchments, modify its runoff generation, and change its dynamic water storage (Brown et al., 2005; 
Hrachowitz et al., 2021; Seibert et al., 2017). Understanding the role of ecosystems in catchment hydrology is crucial, particularly when investigating the impacts of climate change (e.g. Duethmann et al., 2020). Estimating transpiration at the catchment scale is, however, challenging as plant water uptake is difficult to measure, parameterize and scale up from the individual plant to the ecosystem level (e.g. Mencuccini et al., 2019). As a consequence, the predictive performance of hydrological models, which represent water balance and vegetation dynamics in a physically consisted manner, can be limited due to the a-priori chosen vegetation process parameterizations and parameter values (e.g. Bennett and Nijssen, 2021; Gharari et al., 2021; Mendoza et al., 2015). Improving these uncertain parameterizations requires methods that can combine processbased hydrological models with new information about how plant transpiration varies with environmental conditions.

40 Flux towers provide the state-of-the-art evapotranspiration data to train and validate hydrological models. One caveat in using these measurements is that they represent an effective flux integrating evaporation from the canopy interception store and the soil with plant transpiration. An accurate partitioning of this integral flux into its components is, however, of key importance for improving transpiration modelling under changing conditions (Stoy et al., 2019), including effects of land use changes such as deforestation (e.g. Hrachowitz et al., 2021) and forest regeneration (e.g. Neill et al., 2021). This is a key reason why sap

45 flow is used as independent measurement technique to characterize transpiration dynamics in forest (e.g. Granier and Loustau, 1994) and agriculture ecosystems (e.g. Dugas et al., 1994). While originally established in the plant physiology community, sap flow data have also proven useful in hydrological research. For instance, Renner et al. (2016) showed that stand composition of forests can counteract differences in sap flow on south and north facing slopes leading to similar transpiration rates on both expositions. Hoek van Dijke et al. (2019) found that the Normalized Difference Vegetation Index (NDVI)

50 successfully captured sap flow dynamics during the green-up phase, although it failed under dry conditions. Hassler et al. (2018) highlighted that spatial differences of atmospheric demands and soil moisture only explain a small fraction of observed spatial variation of sap flow, while site specific factors, like geology and aspect, were more important. These finding imply that accounting for relations between vegetation characteristics, hydro-meteorological drivers and catchment properties can improve transpiration estimates and exemplifies the potential of using sap flow data to advance hydrological simulations. The

55 value of sap flow information is emphasised by the growing availability of global open-source sap flow databases (Poyatos et al., 2016) that provides opportunities to develop generalized relations to better inform hydrological models at places where no sap flow data is available.

Plants adapt transpiration depending on atmospheric water demand and supply. One important regulation mechanism is the 60 opening and closing of the pores on their leaves, called stomata, to regulate their $\mathrm{CO}_{2}$ and water vapour exchange with the atmosphere. This process crucially governs the transpiration of plants, which is also reflected by the wide range of stomatal conductance models that are available in hydrological models (e.g. Damour et al., 2010). One issue is that these stomatal conductance models typically rely on several site specific parameters and each approach has its own limitations, rendering the choice of the "right" process parameterization challenging. In this context it is interesting to note that sap flow can, besides 
65 being used to estimate transpiration directly, also be used to infer canopy conductance or stomatal conductance scaled by leaf area index (LAI). This is done by inverting a simplified formulation of either Fick's Law or the Penman-Monteith equation (e.g. Ewers and Oren, 2000; Köstner et al., 1992; Phillips and Oren, 1998).

While the complex interactions between soil water supply, vegetation behaviour and meteorology are challenging to parameterize in bottom-up empirical or physically based stomatal conductance models, machine learning methods have recently proven to be a particularly useful alternative to reproduce ecohydrological behaviour and estimate transpiration (e.g. Fan et al., 2021; Zheng et al., 2021). However, despite their recent success, machine learning approaches also have shortcomings as they do not ensure mass and energy conservation and lack physical constraints. The latter renders extrapolation and simulation under changing boundary conditions challenging. Hybrid models that combine physical knowledge of process equations with the flexibility of data driven predictions are therefore a promising tool to estimate fluxes and state variable in the earth system (e.g. Reichstein et al., 2019).

In this study, we propose and test a hybrid machine learning approach to integrate sap flow data into process-based hydrological model, and explore opportunities for improving soil moisture and transpiration estimates at the catchment scale. Specifically,

80 we leverage an extensive sap flow dataset, spanning a drought period, in a sub catchment of the well-monitored and wellstudied Attert experimental observatory (Pfister et al., 2002). We first integrate canopy conductance inferred from sap flow data into a process based hydrological model and compare its performance to the reference model that uses an empirical stomatal conductance equation. We then train a deep learning network based on standard hourly meteorological data, to predict sap flow beyond the temporal extent of the training period. These simulated velocities are then used to estimate canopy conductance, allowing us to replace the empirical stomatal conductance equation in the hydrological model on forward simulations beyond the monitoring periods. Our results support the value of such hybrid model approaches by comparing the different model variants against each other and against hydrological data such as soil moisture and discharge. Importantly, we highlight the value of sap flow measurement campaigns for improving simulation at the catchment scale.

\section{Materials and methods}

\subsection{Study area}

The Weierbach is a $0.44 \mathrm{~km}^{2}$ large experimental headwater catchment, nested in the Colpach catchment and located in Luxembourg (Hissler et al., 2021). The catchment is characterized by coarse-grained and highly permeable soils and a slate bedrock (Ardennes massif). The climate is temperate semi-marine, mean annual rainfall is 950 mm and mean monthly temperatures range between $0^{\circ} \mathrm{C}$ in January and $17^{\circ} \mathrm{C}$ in July. Precipitation is evenly distributed across the seasons while the 
March (Loritz et al., 2021). The Weierbach catchment is entirely forested and dominated (>70\%) by deciduous beech trees (Fagus sylvatica) and oak trees (Quercus spec). A detailed description of the Weierbach catchment and a comprehensive open access hydrological data set can be found in Hissler et al. (2021). The Colpach is the parenting catchment of the Weierbach, located in the same hydro-pedological area and characterized by a similar runoff generation and formation (Loritz et al. 2019), but it comprises a larger variety of land cover types (65\% forest, $35 \%$ agriculture).

\subsubsection{Hydro-meteorological data}

This study requires hourly meteorological data to force the water balance simulations and to calculate canopy conductance. For all these purposes, we use data records from April 2014 to October 2016. We obtain air temperature $\left({ }^{\circ} \mathrm{C}\right)$, relative humidity (\%) and rainfall data $\left(\mathrm{mm} \mathrm{hr}^{-1}\right)$ from the Holtz meteorological station available in the open-access dataset from Hissler et al.

105 (2021). We obtain wind speed $\left(\mathrm{m} \mathrm{s}^{-1}\right)$ and global radiation $\left(\mathrm{W} \mathrm{m}^{2}\right)$ measurements from a meteorological station around $500 \mathrm{~m}$

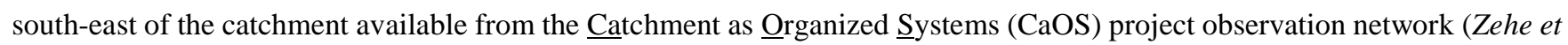
al., 2014). Additionally, we use discharge data and averaged soil moisture from Hissler et al. (2021) at 10 and $60 \mathrm{~cm}$ depth (based on six individual sensors in each depth) to quantify the performance of hydrological model simulations. Soil moisture was additionally corrected for a stone content of 10 and $30 \%$ in 10 and $60 \mathrm{~cm}$ based on several soil profiles in the research area (Jackisch, 2015).

\subsubsection{Sap velocity measurements}

We use hourly sap velocities $\left(\mathrm{cm} \mathrm{h}^{-1}\right)$, the rate of water flow through a tree, from three growing seasons (April - October; 2014 - 2016) of an extensive measurement campaign in the Colpach catchment (detailed description in Hassler et al., 2018). We use a subset of the original data set of Hassler et al. (2018) comprising 32 trees, including 17 beech trees (Fagus sylvatica),

11511 oaks (Quercus spec.), 2 hornbeams (Carpinus betulus) and 2 common alders (Alnus glutinosa) with individual tree diameters at breast height ranging from 8 to $80 \mathrm{~cm}$ (average $32 \mathrm{~cm}$ ). Sample distribution ranges from north to south facing slopes and up- and downslope sectors, specifically selected to capture the typical hydro-pedological characteristics of the Colpach and the Weierbach. The campaign equipped each tree before leaf out of the growing season with sap flow sensors, manufactured by East 30 (Washington, USA). The sensors have three measurement depths, at 5, 18 and $30 \mathrm{~mm}$ in the xylem

120 and measure sap velocity with the heat ratio method (Campbell et al., 1991, Burgess et al. 2001; Hassler et al 2018). We estimate tree-specific sap velocities by calculating the median from the measurements at the three different xylem depths. We use the median to account for the skewed distribution of sap velocities inside the sap wood, as sap velocities typically decrease closer to the heartwood (e.g. Gebauer et al. 2008, Jackisch et al. 2020). 


\subsubsection{Catchment-level sap flow based transpiration}

125 This study focuses on catchment-level transpiration to circumvent the challenge and uncertainty of characterizing transpiration from individual tree sap flow (e.g. Gebauer et al., 2008; Zhang et al., 2015) and to remain scale consistent with simulated transpiration of the hydrological model. We employ an integral approach, assuming that the tree sample is representative for the age spectrum in the catchment and that trees dominate transpiration in this forested catchment compared to understory and herbaceous vegetation. We average the 32 tree-specific sap velocities to obtain a time series representing an average tree in

130 the study area. We then obtain average hourly catchment-level sap flow based transpiration per unit ground area $\left(T_{\text {sap }}\right.$, $\left.\mathrm{m} \mathrm{s}^{-1}\right)$

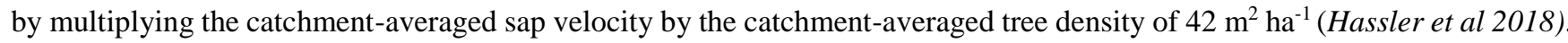
This calculation assumes that water storage in the tree relative to the transpiration flux is negligible. Therefore, the observed daytime water flux through the tree is equal to the transpiration flux through the leaves into the atmosphere, with negligible time lags between dynamics of sap flow (converted to $T_{\text {sap }}$ ) and environmental variables (Tyree and Ewers, 1991). We use

$135 T_{\text {sap }}$ data to derive observation-based canopy conductance estimates and to evaluate model simulations.

\subsection{Hydrological model CATFLOW}

We model the water balance of the Weierbach with CATFLOW (Maurer, 1997; Zehe et al., 2001), a process-based hydrological model. CATFLOW discretizes hillslopes along a 2-dimensional cross-section using curvilinear orthogonal coordinates and a storage weighting function to represent the varying hillslope width. The model simulates soil water dynamics

140 based on the Darcy-Richards equation and represents surface runoff by a diffusion wave approximation of the Saint-Venant equation. CATFLOW estimates three components of the evapotranspiration flux per unit ground area, namely 1) direct evaporation of canopy interception, 2) transpiration from canopy leaves and 3) soil water evaporation, separately with a surface energy balance approach using the Penman-Monteith equation. For each component, soil, canopy (section 2.2.2) and canopy interception conductances are each parameterized differently with a set of empirical equations. Additional CATFLOW model descriptions can be found in Loritz et al. (2021) and in Loritz et al. (2017).

\subsubsection{CATFLOW implementation of three canopy conductance variations}

We implement three approaches to estimate canopy conductance in the Penman-Monteith equation for transpiration in CATFLOW. The reference model implements canopy conductance calculated by the empirical Jarvis-Stewart equation, which is the built-in stomatal conductance equation of CATFLOW ( $g_{c} J a r v i s$; section 2.2.2) scaled by the LAI. The second model

150 variant is a model-data integration, which implements canopy conductance based on hourly observed sap flow data for all three growing seasons from 2014 to 2016 ( $g_{c}$ sap; section 2.2.3). The third model variant is a hybrid model, which implements canopy conductance based on sap flow predictions from a deep learning network ( $g_{c} D L$; section 2.2.4). 


\subsubsection{Reference model: Canopy conductance from the reference empirical canopy conductance equation ( $\left.g_{c} J a r v i s\right)$}

155 The Jarvis-Stewart model (Jarvis, 1976; Stewart, 1988) is a widely applied empirical equation for stomatal conductance as a function of plant available radiation $\left(\mathrm{W} \mathrm{m}^{-2}\right)$, vapour pressure deficit $(\mathrm{Pa})$, temperature $\left({ }^{\circ} \mathrm{C}\right)$, matric water potential of the soil $(\mathrm{m})$, and is implemented in CATFLOW. The canopy conductance per unit ground area ( $g_{c}$ Jarvis) is calculated from the leaflevel stomatal conductance scaled by leaf area index (LAI, $\mathrm{m}^{2}$ leaf $\mathrm{m}^{-2}$ ground). Parameters of the Jarvis-Stewart model are prescribed according to a lookup table and are based on mean parameter values (e.g. rooting depth, plant albedo, interception capacity, etc.) for beech trees taken from Breuer et al. (2003). LAI measurements are taken from satellites observations and change daily (Visible Infrared Imaging Radiometer Suite; VIIRIS). The model variant that uses $g_{c} J a r v i s$ to estimate transpiration serves as reference model in this study.

\subsubsection{Model-data integration: Canopy conductance from sap velocity measurements $\left(g_{c} s a p\right)$}

We use a big-leaf approach, in line with most catchment-scale transpiration models, to infer conductance to water vapour per unit ground area $\left(g_{c} s a p ; \mathrm{m} \mathrm{s}^{-1}\right)$ from sap velocity and meteorological data (wind speed, air temperature, and relative humidity). We assume a well-mixed, convective boundary layer during daytime, with high wind speed, small leaves, and similar leaf and air temperature. Given these common simplifying assumptions (e.g. Ewers and Oren, 2000; Köstner et al., 1992), we neglect leaf boundary layer conductance and approximate the difference in water vapour concentration driving the vapour diffusion through the saturated air space in the leaves to the atmosphere by the air vapour pressure deficit $\left(e_{s}-e_{a} ; \mathrm{Pa}\right)$. Hence, we can invert Fick's Law following Monteith and Unsworth (2013) to calculate total water vapour conductance $g_{t}$ sap $\left(\mathrm{m} \mathrm{s}^{-1}\right)$ as:

$$
g_{t} \operatorname{sap}=\frac{\gamma \lambda}{C_{p} \rho\left(e_{s}-e_{a}\right)} T_{\text {sap }}
$$

where $\gamma$ is the psychometric constant $\left(\mathrm{Pa} \mathrm{K}^{-1}\right) ; \lambda$ is the latent heat of vaporization of water $\left(\mathrm{MJ} \mathrm{kg}^{-1}\right) ; C_{p}$ is the specific heat

of air $\left(\mathrm{J} \mathrm{kg}^{-1} \mathrm{~K}^{-1}\right) ; \rho$ is air density $\left(\mathrm{kg} \mathrm{m}^{-3}\right) ; \gamma, \lambda, C_{p}, \rho$ are all a function of air temperature; and $T_{\text {sap }}\left(\mathrm{m} \mathrm{s}^{-1}\right)$ is the average catchment transpiration rate derived from sap velocities.

The total conductance $g_{t} s a p$ represents the series of both $g_{c}$ sap and the aerodynamic conductance $\left(g_{a}, \mathrm{~m} \mathrm{~s}^{-1}\right)$. The latter is estimated from wind speed and canopy height following the FAO reference approach (Allen et al. 1998). Finally, we obtain the time series of canopy conductance $g_{c}$ sap inferred from sap velocities as:

$\frac{1}{g_{c} \operatorname{sap}}=\frac{1}{g_{t} \operatorname{sap}}-\frac{1}{g_{a}}$ 
180 This big leaf approach assumes that all canopy leaves in the catchment respond to the same environmental conditions and behave in the same way. This is reasonable, because hydro-meteorological data explained only a small fraction of spatial variability in sap flow velocities in the study site (Hassler et al 2018).

We implement canopy conductance inferred from observed and simulated sap velocities $\left(g_{c} s a p, g_{c} D L\right.$ explained in section 185 2.2.4) in CATFLOW only during the time steps for which the assumptions of Eq (1) are met (Köstner et al., 1992; Phillips and Oren, 1998): dry canopy (canopy interception storage < $0 \mathrm{~mm}$ ); daytime (between 6:00 and 22:00); well-mixed atmosphere

$\left(\frac{1}{g_{a}}\right.$ is at least $10 \mathrm{~s} \mathrm{~m}^{-1}$ larger than $\left.\frac{1}{g_{t}}\right)$; air vapour pressure deficit $>100 \mathrm{~Pa}$. When these conditions are not met, the transpiration flux and stomatal conductance are generally low and we fill in the gaps with canopy conductance estimates from the built-in Jarvis-Stewart model. We smooth canopy conductance time series inferred from observed and predicted sap velocities using a rolling mean with a three hour window that uses the three previous time steps to allow forward simulations.

\subsubsection{Hybrid model: Canopy conductance from deep learning based sap flow predictions $(g c D L)$}

We train a deep learning model to estimate hourly sap flow using the 2014 and 2016 data for training and the growing season of 2015 for testing. We choose the 2015 growing season as the test period because it has been identified as a drought year, during which transpiration was impacted by plant water stress (Hoek van Dijke et al., 2019). The deep learning network is driven by the same hourly meteorological inputs as catchment models (temperature, relative humidity, global radiation, rainfall and wind speed). Additionally, the deep learning uses a sequence length of 96 (lag time of 96 hours preceding the prediction time step). Input and target features are standardized by subtracting their means and scaling by their standard deviations. The network consists of four layers (input, two hidden, output) with 128 cell/hidden states. The input and first hidden layer of the network use gated recurred units (GRUs); are followed by a second hidden linear layer with a relu activation function; finally the output is a linear layer without an activation function. Between each layer we add $10 \%$ dropout to avoid overfitting to the training data (regularization). The structure of the network is identified by trial and error. We use the mean-square error as loss function, train the model in 500 epochs with a batch size of 360 and report the root mean square error (rmse) in the results. We use an ADAM optimizer with a fixed learning rate schedule. The initial learning rate is set at $1 \mathrm{e}-3$ and decreases by a factor of 0.95 after each epoch. Additionally, after the 400 epoch we use a stochastic weight averaging (SWU) approach with a learning rate of 0.001 to improve the ability of the network to generalize in comparison to using exclusively an ADAM optimizer. We use the simulated sap flow velocities to estimate $g_{c} D L$ using the same method and under the same environmental condition as applied to estimate $g_{c} \operatorname{sap}($ Eq. 1-2).

\subsubsection{CATFLOW parameterization}

We use the well-tested, representative hillslope model from Loritz et al. $(2017,2021)$ to simulate the water balance of the 210 Weierbach using CATFLOW. The representative hillslope model was setup based on field data for the bedrock topography, 
soil properties and surface topography. The model was fine-tuned by exclusively adjusting the spatially explicit macropore network (approach described in detail in Wienhöfer and Zehe, 2014) with the goal of matching the seasonal water balance and the hydrograph of the parenting Colpach catchment during the hydrological year October 2013 to October 2014. Loritz et al. (2017) showed that the representative hillslope model predicts the hydrograph of the Weierbach with a Nash-Sutcliff efficiency (NSE) of $\approx 0.7$ and a Kling Gupta efficiency of $\approx 0.8$ for the hydrological year 2012/13 (test period) and the hydrological year 2013/14 (training period) individually.

The simulation period in this study starts on the $1^{\text {st }}$ of April 2014 and runs until $31^{\text {th }}$ October 2016 . This is preceded by a model spin-up starting in October 2013 with initial states of $70 \%$ volumetric water content. We are using the exact same parameterization as explained in detail in our previous studies (Loritz et al., 2017, 2021) and do no re-calibration of any model parameters besides changes described above to estimate the canopy conductance.

\section{Results}

\subsection{Sap flow data-model integration provides realistic canopy conductance and water balance estimates for a temperate beech forest}

225 The daily averaged canopy conductance $\left(\mathrm{m} \mathrm{s}^{-1}\right)$ inferred from the sap flow measurements $\left(g_{c} s a p\right)$ and those estimated by the a-priori parameterized CATFLOW built-in stomatal conductance equation ( $g_{c} J a r v i s$ ) correlate well, although $g_{c} J a r v i s$ estimates are on average lower (Fig. 1a). Regardless, the spearman rank correlation between $g_{c} J a r v i s$ and $g_{c}$ sap is 0.85 and the rmse is $0.01 \mathrm{~m} \mathrm{~s}^{-1}$. The $g_{c}$ sap estimates are within a reasonable range for a beech-dominated temperate forests and comparable to literature values using a similar approach (inverse Penman-Monteith equation) based on six beech trees in the Czech

230 Republic (Su et al. 2019). Differences between $g_{c}$ Jarvis and $g_{c} s a p$ are also reflected, although weaker, in the monthly transpiration estimates (Fig. 1 b). The CATFLOW model variant using $g_{c} s a p$ (model-data integration) estimates about $130 \mathrm{~mm}$ more transpiration compared to the reference model variant using $g_{c}$ Jarvis for all three hydrological years, with the largest monthly difference of $21 \mathrm{~mm} \mathrm{month}^{-1}$ in May 2015 (31 mm of total rainfall in May 2015).

235 Implementing $g_{c}$ sap instead of $g_{c}$ Jarvis in CATFLOW has only a weak effect on simulated runoff with a slight decline of the NSE from 0.75 to 0.71 over the three-year period. This decrease in predictive performance likely occurs because the macropore network was tuned to optimize the streamflow of the Weierbach with $g_{c} J a r v i s$ and not $g_{c} s a p$. This entails that a better performance could likely be achieved by tuning the macropore network once more with $g_{c} s a p$. However, we do not to perform further CATFLOW calibrations because our goal is to demonstrate the value of sap flow data in improving transpiration and soil moisture estimates and do not aim to obtain the highest performance in streamflow simulation. 

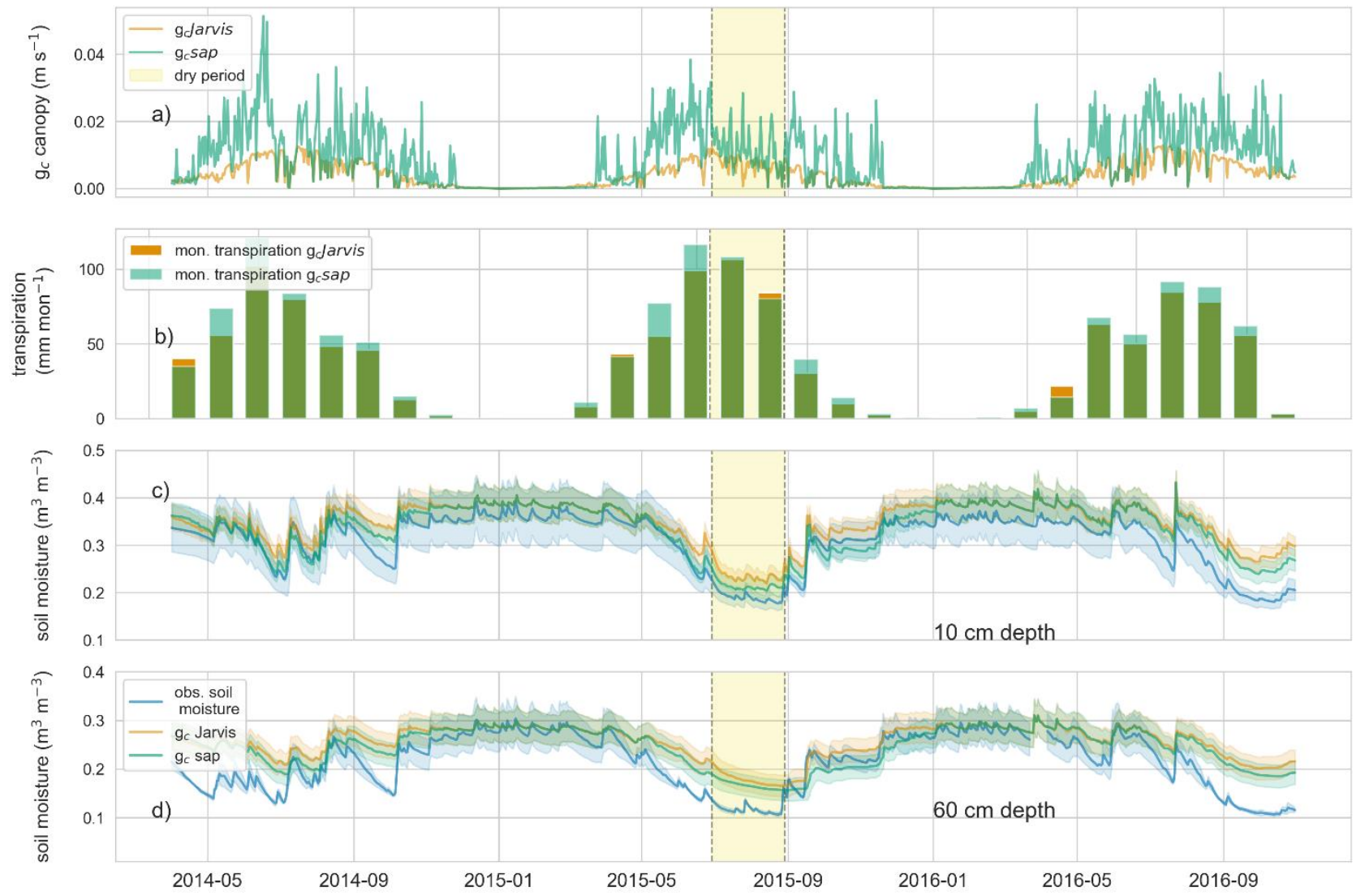

Figure 1. a) daily averaged canopy conductance estimates for $g_{c s a p}$ (green) and $g_{c} J a r v i s$ (orange); b) monthly transpiration sums estimated using $g_{c s a p}$ (green) and $g_{c} J a r v i s$ (orange); observed (blue) and simulated soil moisture \pm standard deviation of the corresponding simulation and observations ( $g_{c} s a p$ : green; $g_{c} J a r v i s$ : orange) at 10 (c) and $60 \mathrm{~cm}$ depth (d). Highlighted in yellow is a dry period from July to August 2015.

\subsection{Ecohydrological simulations differ most during drought periods}

Noticeable ecohydrological relevant model improvements using $g_{c} s a p$ occur during drought periods. The Weierbach fell dry on 61 days $\left(>0.001 \mathrm{~mm} \mathrm{~h}^{-1}\right)$ during the three year record. This period is only slightly overestimated by CATFLOW using $g_{c}$ sap (63 days), while it is substantially underestimated using the reference model with $g_{c}$ Jarvis (46 days). Both model variants

( $g_{c}$ Jarvis and $g_{c} s a p$ ) correlate well with the observed soil moisture in 10 and $60 \mathrm{~cm}$ with Spearman rank coefficients of around 0.9. However, simulations using $g_{c}$ sap result in overall lower soil moisture values with the largest difference in October 2015

(Fig. $1 \mathrm{a}$ and b). Using $g_{c} s a p$ instead of $g_{c}$ Jarvis reduces the rmse in the 2015 growing season from 0.033 to 0.01 (0.046 to 0.034) $\mathrm{m}^{3} \mathrm{~m}^{-3}$ at 10 (and 60) $\mathrm{cm}$ depth. Furthermore, using $g_{c}$ sap instead of $g_{c}$ Jarvis leads to an average of about $2 \mathrm{~mm}$ less catchment storage after each of the three growing seasons. These storage differences are almost completely recharged in winter, typically until January, due to the wet autumns in the region. However, after the three growing seasons, the bedrock water 
storage (characterized by very low hydraulic conductivities and low porosities) is on average 2 to $4 \%$ lower when using $g_{c} s a p$ compared to $g_{c} J a r v i s$ after three years of simulations.

\subsection{Deep learning accurately extrapolates sap flow data to different time periods and locations}

Fig.2 a displays hourly simulated sap flow $\left(\mathrm{cm} \mathrm{h}^{-1}\right)$ estimated by the deep learning model against observed sap flow $\left(\mathrm{cm} \mathrm{h} \mathrm{h}^{-1}\right)$ at daytime (6:00 and 22:00) of the growing season 2015 (test period). Simulated sap flow differs from observed sap flow by an rmse of $0.8 \mathrm{~cm} \mathrm{~h}^{-1}$ during the training period (growing seasons 2014 and 2016) and $1.1 \mathrm{~cm} \mathrm{~h}^{-1}$ during testing period. The spearman rank correlation between the observed and simulated sap flow in the test period is 0.91 , indicating the ability of the deep learning model to capture the general dynamics of sap flow using hourly meteorological data as predictors. Sap flow during the dry spell in July and August 2015 is on average overestimated by the deep learning model. However, when adding randomly picked 15 continuous days of the dry period to the training sample (and removing those from the test sample) this bias and the rmse are significantly reduced to $0.85 \mathrm{~cm} \mathrm{~h}^{-1}$. Furthermore, we also tested the ability of the deep learning network to predict sap flow in a nearby catchment with a different geological and pedological setting but similar forest landcover. This first test suggests that the deep learning network can predict sap flow also in this test catchment even with lower errors as in the training catchment. This good out of sample performance points to the algorithm's ability to also extrapolate to higher unseen sap flows without further training (Appendix A1).

\subsection{The hybrid model provides accurate canopy conductance and water balance estimates}

The canopy conductance inferred from the observed sap flow $\left(g_{c} s a p\right)$ and based on the simulated sap flow $\left(g_{c} D L\right)$ are compared in Fig. 2 b. The two estimates differ by a rmse of $0.01 \mathrm{~m} \mathrm{~s}^{-1}$ in the test period and have a Spearman rank correlation of 0.9 . The relation between the conductance estimates based on observed, $g_{c} s a p$, and simulated sap flow, $g_{c} D L$; is characterized by more and stronger outliers (residual larger than $0.025 \mathrm{~m} \mathrm{~s}^{-1}$, Fig. 2 b). Note that more than $75 \%$ of these outliers occur in the morning (6:00 to 10:00) or evening time (16:00 to 22:00). During these times, the Fick's law approximation is very sensitive to little changes in sap velocities but transpiration is typically very low during these periods. This is further underpinned by the comparison of monthly transpiration sums displayed in Fig. 2 c. The differences in using $g_{c} \operatorname{sap}$ or $g_{c} D L$ are less than 3 mm month $^{-1}$ during the majority of the growing season 2015 and increase only in July and August to 7 and $9 \mathrm{~mm} \mathrm{month}^{-1}$. In this period, sap flow and to a smaller extent the corresponding $g_{c}$ values are systematically overestimated by the deep learning network (Fig.2 a). As stated above, adding 15 dry days to the training data can reduce these biases and decrease the transpiration differences in July and August below $4 \mathrm{~mm}$ month $^{-1}$. However, even without changing the training data of the deep learning network, the effect on simulated soil moisture dynamics is minor (Fig. $2 \mathrm{~d}$ ). This is because the $g_{c} D L$ based model slightly underestimates transpiration in May and June, which is then compensated in July and August and the simulated soil moisture

285 from $g_{c} D L$ and $g_{c}$ sap differ only by a rmse of $0.003 \mathrm{~m}^{3} \mathrm{~m}^{-3}$ in 20 and $0.002 \mathrm{~m}^{3} \mathrm{~m}^{-3}$ in $40 \mathrm{~cm}$ from $1^{\text {st }}$ May 2015 to $31^{\text {th }}$ October 2015. 


\subsection{The hybrid model improves the diurnal cycle of canopy conductance compared to the reference model}

Fig. 3 shows three diurnal cycles of $g_{c}$ Jarvis, $g_{c}$ sap and $g_{c} D L$ in June, July and August. $g_{c} s a p$ is about twice as high in June compared to August and shows a stronger decline in conductance during midday in July and August. While such patterns are typical for humid forests under dry conditions (Su et al., 2019), they are not or only weakly captured by the Jarvis-Stewart model ( $g_{c}$ Jarvis), which suggests a relatively constant conductance during day time. As already indicated by the high correlation between $g_{c} D L$ and $g_{c} s a p$, the former also captures the dynamics of the diurnal cycles well. However, the $g_{c} D L$ model under- or overestimates several peaks, particular during the morning and evening hours. This is in line with Fig. $2 \mathrm{~b}$ and explains the larger spread of the $g_{c}$ estimates in contrast to sap flow predictions. The absolute cumulated difference of the transpiration estimates using either $g_{c} D L$ or $g_{c} s a p$ in the chosen three-day period is with $0.01,0.014$ and $0.07 \mathrm{~mm}_{\text {day }}{ }^{-1}$ low and highlights that errors in $\mathrm{g}_{\mathrm{c}}$ estimates in the morning and evening are less important for transpiration estimates.
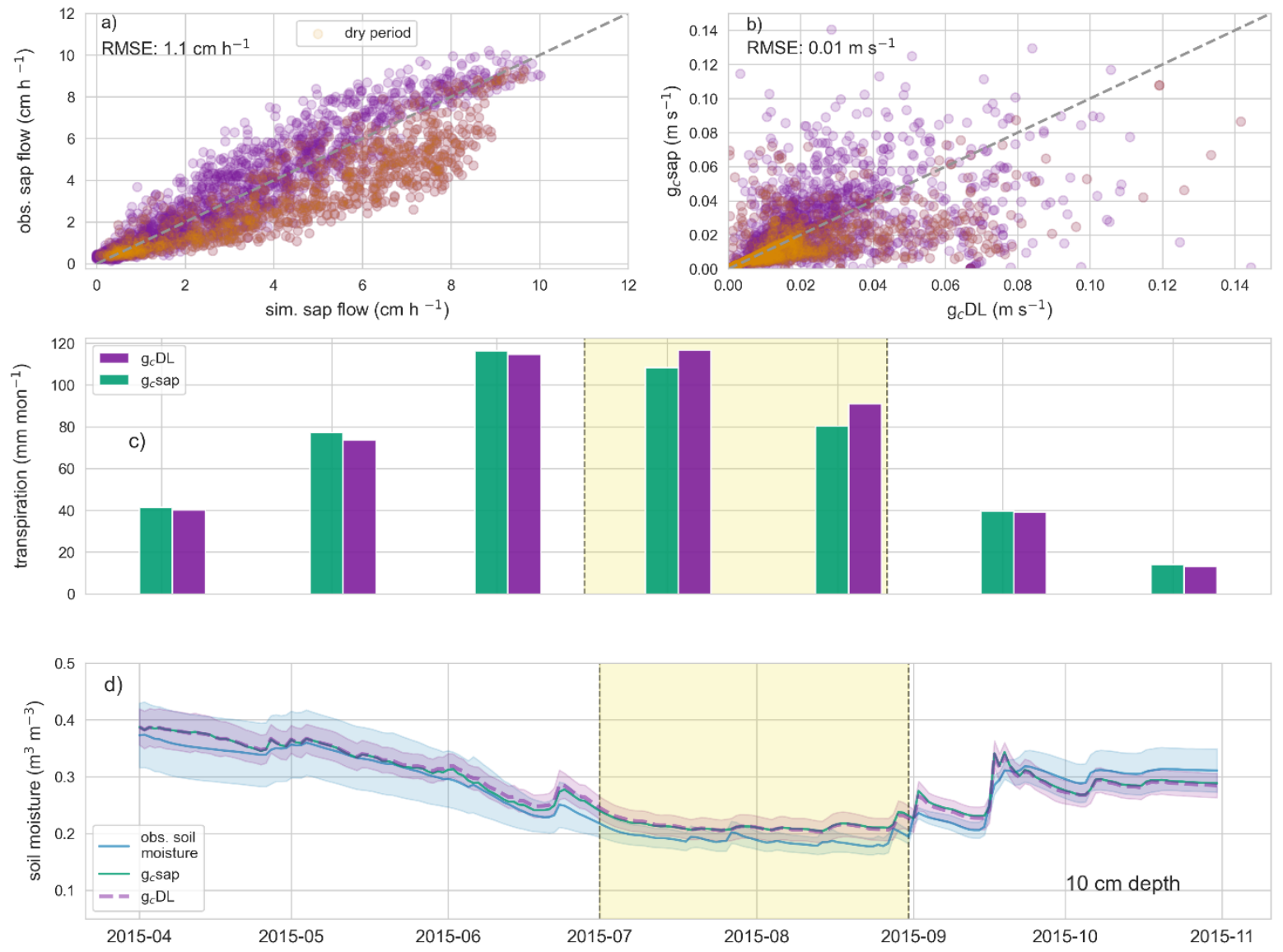

300 Figure 2. a) hourly observed catchment-averaged sap flow and simulated sap flow in the growing season 2015; b) hourly canopy conductances based on the hourly observed sap flow $\left(g_{c}\right.$ sap $)$ and simulated sap flow $\left(g_{c} D L\right)$; orange points in a and b are simulations 
or observations within the dry period of July and August 2015; c) monthly transpiration sums estimated by $g_{c} s a p$ (green) and $g c D L$ (purple); d) observed (blue) and simulated soil moisture ( $g_{c s a p}$ : green; gcDL: purple) in $20 \mathrm{~cm}$. Highlighted in yellow is a dry period from July to August in the growing season 2015.
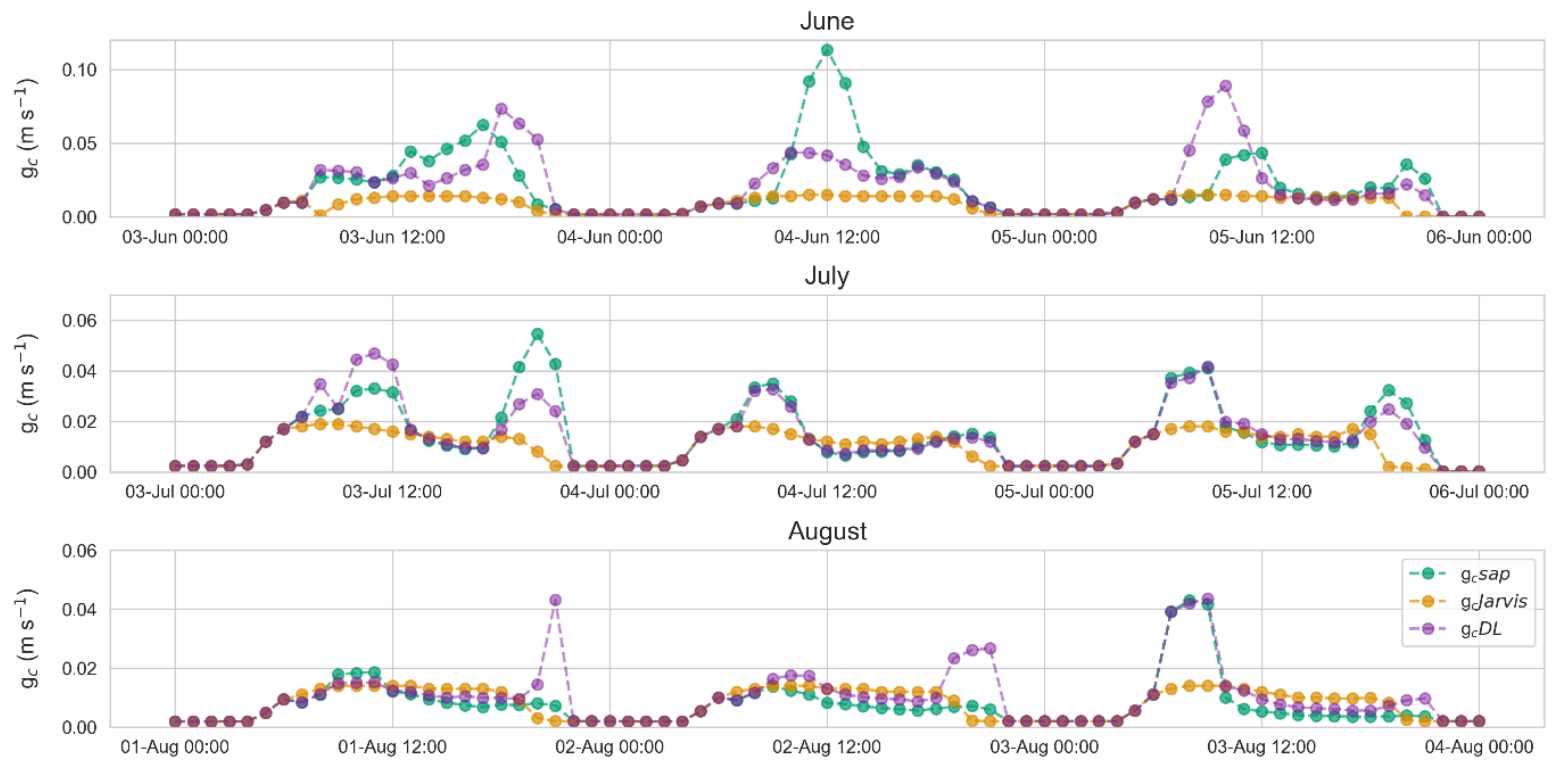

Figure 3. Hourly canopy conductances of $g_{c}$ sap (green), $g_{c} J a r v i s$ (orange) and $g_{c} D L$ (purple) for three selected days in June, July and August in the growing season 2015.

\section{Discussion}

\subsection{Integrating sap flow data in a catchment-scale hydrological model}

310 The comparison between both stomatal conductance models revealed that the a-priori parameterized Jarvis-Stewart model (Jarvis, 1976; Stewart, 1988), in combination with the satellites based VIIRIS LAI values, clearly underestimated the canopy conductance, particularly during the spring and early summer. This bias could potentially be corrected by tuning the parameters of the Jarvis-Stewart equation. However, beyond revealing absolute errors in the seasonal cycle, the sap flow based stomatal conductance model also demonstrates that the Jarvis-Stewart model is not able to reproduce diurnal hydraulic feedbacks

315 reflected in the dips in canopy conductance during the mid-day water stress period. Simulating these dips would, most likely, require a more complex stomatal conductance model. On the other hand theses dynamics are embedded in the sap flow data and were well reproduced by the deep learning network. Therefore, learning this information from sap flow data with a deep learning network provides an avenue for catchment models to reproduce plant hydraulic behaviour without explicitly parameterizing the soil-plant-atmosphere continuum at the catchment scale, which is complex and uncertain (Mencuccini et al., 2019). 
Our results go beyond the established approach of estimating canopy conductance from sap flow data by directly integrating the data in a catchment-scale hydrological model and improving water balance simulations. Additionally, we can demonstrate the value of sap flow data in identifying suitable catchment-specific model parameterizations (Gupta et al., 1999) and show how the stomatal conductance model can be replaced by a data model integration. Using the sap flow to calculate canopy conductance instead of transpiration has thereby the advantage of omitting species-dependent errors in estimating the sap wood area and sap velocity distributions within the xylem. Faulty estimates of these parameters can lead to an overestimation of daily water use of up to $78 \%$ for oak trees and $-42 \%$ in case of oriental arborvitae trees as shown by Zhang et al. (2015). Nevertheless, the results of the deep learning network underpin the possibility to predict sap flow with a machine learning approach. This approach could then be extended to estimate transpiration based on catchment averaged species dependent parameters, which could, for instance, be estimated by LiDAR measurements (Fassnacht et al., 2016).

\subsection{Predicting canopy conductance using sap flow and a deep learning network}

Recent studies have shown the large potential of decision tree based machine learning algorithms for ecohydrological applications with a focus on predicting sap flow (Ellsäßer et al., 2020) or stomata conductances (Saunders et al., 2021) using meteorological data. In this study, we showed that deep learning networks are also suitable tools to predict sap flow by exclusively using meteorological variables as input. Only during the dry period in the growing season 2015 where the dormant trees most likely experienced water stress (Hoek van Dijke et al., 2019) did the deep learning network systematically overestimate sap flow. The latter was the reason to choose 2015 as test period and not 2016, which would have kept the chronological order and led to overall lower errors without bias. Initial tests reveal that adding randomly picked 15 continuous days during the drought period to the model training can reduce the residuals as well as the bias significantly, although soil moisture data were still not included as input. This indicates the potential of the deep learning networks to mimic sap flow also under water stress and solely based on meteorological input. The latter entails that the information about the drought period is already within the meteorological input and different aggregations and combinations of the input variables, for instance, by estimating drought indices like the standardized precipitation index (SPI) could potentially further improve the prediction of sap flow under limited water availability. This study highlights thereby the potential of the introduced deep learning approach, but a more systematic investigation is required. Specifically, a next step could be to explore the potential of implementing the deep learning network such that the internal hydrological model states (especially soil water status) affect the sap flow predictions and the corresponding conductances. A similar hybrid modelling approach has, lately shown large potential to represent turbulent heat fluxes in hydrological models (Bennett and Nijssen, 2021).

\subsection{Generalizing canopy conductance models based on sap flow data}

350 This study is based on an unique data set with several sap flow sensors installed in different trees and locations as well as over several growing seasons (Hassler et al., 2018). Such data sets are labour intensive and rare although sap flow monitoring has 
become more common. While our proof of concept is limited to well-monitored experimental catchments, initial tests show that the deep learning network is capable of reproducing sap flow in a neighbouring catchment, characterised by a similar forest structure but different hydro-pedological setting, even with lower residuals (Appendix A1). Approaches like transfer leaning, a concept to pre-train layers in a deep learning network on a large data set and only fine tune a subset of these layers in the destination area, might be used to predict sap flow also in a catchment with very little sap flow data available. Additionally, global and open data sets like SAPFLUXNET (Poyatos et al., 2016) in combination with catchment or forest properties offer opportunities to generalize our proposed approach .While machine learning predictions cannot directly advance understanding of the soil-plant-atmosphere continuum, we nevertheless show that they can be an improvement compared to reference empirical models that, if ill parameterized (e.g. Mencuccini et al., 2019; Mendoza et al., 2015), are known to poorly capture non-linear responses of plant water stress at the seasonal and diurnal time scales. Using machine learning sap flow predictions in combination with the inversed Fick's law offers hence the possibility to replace stomatal conductance models entirely in hydrological models.

\section{Conclusion}

365 The main findings from our study leveraging sap flow data in a catchment-scale model are as follows:

1. Hourly, catchment averaged sap flow can be used to estimate canopy conductance and inform a process based hydrological catchment model to improve soil moisture and transpiration estimates.

2. Seasonal and diurnal model improvements were notable during drought periods when the reference empirical model underestimated plant water stress and point to the valuable ecohydrological information encoded in sap flow data.

3. Deep learning networks are suitable tools to predict sap flow by exclusively using meteorological variables as input and offer promising avenues for developing generalized canopy conductance models for forward simulations beyond the monitoring time period and catchment location.

375 This study highlights the potential of sap flow data for improving hydrological simulations at the catchment scale by either constraining or informing hydrological models. We argue that sap flow sensors measure crucial information about one of the major fluxes of the hydrological cycle and should become the norm in experimental hydrology as soil moisture sensors, piezometer or gauging station are already today. 
https://doi.org/10.5194/hess-2022-62

380 Code and data availability. All simulation results and the catchment averaged sap flow data are available from the lead author on request and will be made public (e.g. Zenodo) in case the MS is accepted for publication. The entire sap flow data set is available by $\mathrm{SH}$ on request.

Author contributions. RL and MB designed the study and wrote the paper. RL carried out all analysis and model simulations.

385 SH contributed expertise about sap flow measurements and provided the quality-controlled sap flow data. AH and EZ contributed to interpreting results and editing the paper.

Competing interests. EZ and AH are members of the editorial board of Hydrology and Earth System Sciences.

390 Acknowledgements. This research contributes to the Catchments As Organized Systems (CAOS) research group (FOR 1598), funded by the German Science Foundation (DFG ZE 533/11-1, ZE 533/12-1). MB received funding from the European Commission and Swedish Research Council for Sustainable Development (FORMAS) (grant 2018-02787) in the frame of the international consortium iAqueduct financed under the 2018 Joint call of the WaterWorks2017 ERA-NET Cofund. 


\section{Appendix}

\section{A1 Sap flow predictions in Huewelerbach}

The Huewelerbach is a $2.7 \mathrm{~km}^{2}$ large headwater catchment located in Luxembourg within the experimental Attert basin (Pfister et al., 2002). The prevailing geology is sandstones above an impermeable layer of clay stones. The climate is temperate semioceanic, mean annual rainfall is $845 \mathrm{~mm}$ (Pfister et al., 2017) and mean monthly temperatures range between $0^{\circ} \mathrm{C}$ in January and $17^{\circ} \mathrm{C}$ in July. The catchment is entirely forested and dominated by deciduous beech trees. Meteorological data to run the deep learning network in this Appendix consisted of hourly global radiation $\left(\mathrm{W} \mathrm{m}^{2}\right)$, temperature $\left({ }^{\circ} \mathrm{C}\right)$, wind speed $\left(\mathrm{m} \mathrm{s}^{-1}\right)$ and relative humidity $(\%)$. Temperature and relative humidity are measured at a meteorological station located $3 \mathrm{~km}$ south of the catchment from a station operated by the "Administration des Services Techniques de l'Agriculture" (ASTA). Wind speed and global radiation are measured at a meteorological station in close proximity of the catchment that belonged to the CAOS Project observation network.

We use sap flow velocities from one growing seasons (April - October 2015) measured within or in close proximity to the Huewelerbach catchment. Tree species consist of 27 beech trees (Fagus sylvatica) 7 Oaks (Quercus spec.), and 2 hornbeams (Carpinus betulus) with individual tree diameter at breast height ranging from 22 to $91 \mathrm{~cm}$ (average $53 \mathrm{~cm}$ ). Sap flow was measured and aggregated similarly as described in the method section.

Fig. A1 shows the simulated and observed hourly sap flow in the Weierbach and Huewelerbach for the growing season 2015. Sap flow was predicted using the same deep learning network trained exclusively in the Weierbach (growing season 2014 and 2016). There was no further change to that network. The deep learning network was capable of predicting sap flow in the

415 Huewelerbach in better agreement with the observations than in the training catchment. One main reason for this performance increase is that although in close proximity to the Weierbach the dormant trees in the Huewelerbach did not experience water stress in 2015 most likely due to a large and accessible groundwater store (Hoek van Dijke et al., 2019). Other factors including, as higher quality meteorological data or (potentially) sap flow data might also play a role but were not further investigated. Interestingly, the deep learning network is capable to simulate overall higher sap flow in the Huewelerbach although such

420 values have not been observed in the Weierbach. This supports the ability of the deep learning model to extrapolate in different sites. 
https://doi.org/10.5194/hess-2022-62

Preprint. Discussion started: 18 February 2022

(c) Author(s) 2022. CC BY 4.0 License.
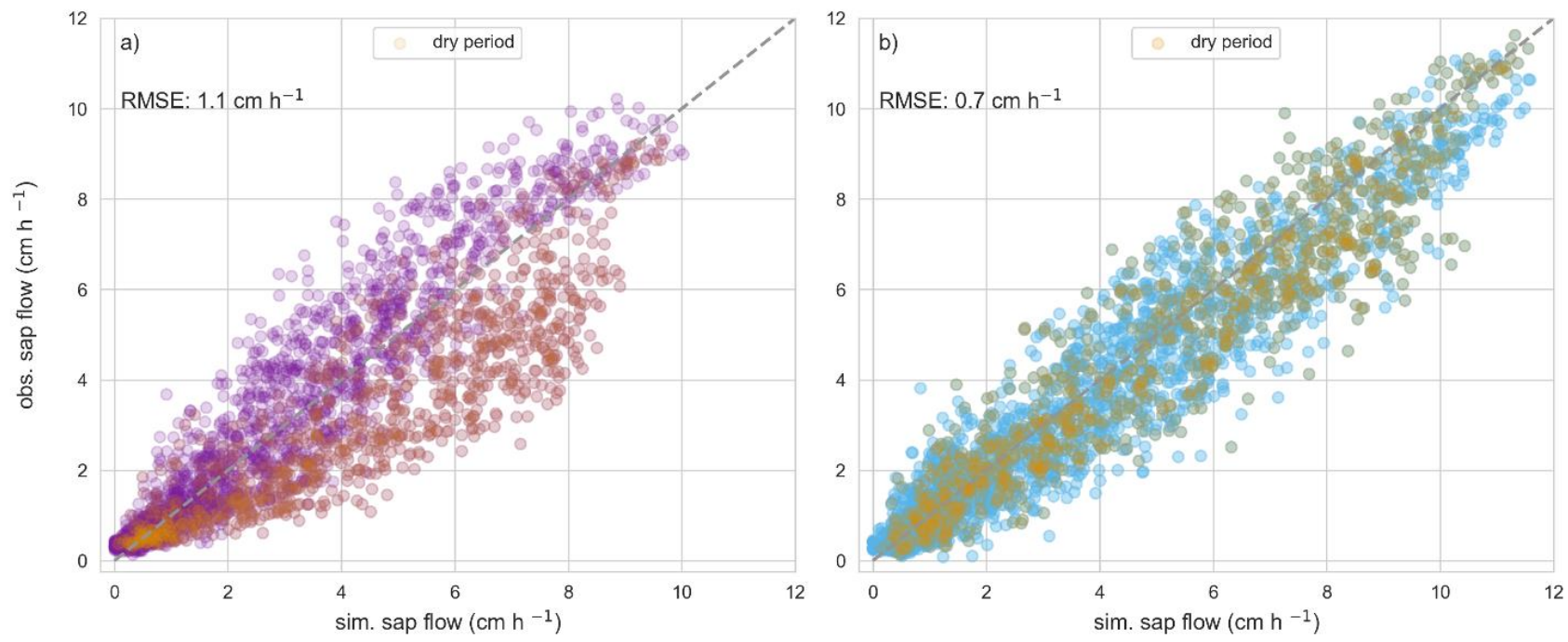

Figure A1 a) hourly observed catchment-averaged sap flow and simulated sap flow in the growing season 2015 in the Weierbach catchment; b) hourly observed catchment-averaged sap flow and simulated sap flow in the growing season 2015 in the Huewelerbach catchment; orange points in a and b are simulations or observations within the dry period of July and August 2015. 


\section{References}

Allen, R. G., Pereira, L. S. and Smith, M.: Crop evapotranspiration - Guidelines for computing crop water requirements, Rome, Italy. [online] Available from: http://www.fao.org/3/X0490E/X0490E00.htm, 1998.

Bennett, A. and Nijssen, B.: Deep Learned Process Parameterizations Provide Better Representations of Turbulent Heat Fluxes in Hydrologic Models, Water Resour. Res., 57(5), 1-14, doi:10.1029/2020WR029328, 2021.

Breuer, L., Eckhardt, K. and Frede, H.-G.: Plant parameter values for models in temperate climates, Ecol. Modell., 169(2-3), 237-293, doi:10.1016/S0304-3800(03)00274-6, 2003.

Brown, A. E., Zhang, L., McMahon, T. A., Western, A. W. and Vertessy, R. A.: A review of paired catchment studies for determining changes in water yield resulting from alterations in vegetation, J. Hydrol., 310(1-4), 28-61, doi:10.1016/j.jhydrol.2004.12.010, 2005.

Damour, G., Simonneau, T., Cochard, H. and Urban, L.: An overview of models of stomatal conductance at the leaf level., Plant. Cell Environ., 33(9), 1419-38, doi:10.1111/j.1365-3040.2010.02181.x, 2010.

Dingman, L. S.: Physical Hydrology, Waveland Press, Inc., 2015.

Duethmann, D., Blöschl, G. and Parajka, J.: Why does a conceptual hydrological model fail to predict discharge changes in response to climate change?, Hydrol. Earth Syst. Sci. Discuss., (January), 1-28, doi:10.5194/hess-2019-652, 2020.

Dugas, W. A., Heuer, M. L., Hunsaker, D., Kimball, B. A., Lewin, K. F., Nagy, J. and Johnson, M.: Sap flow measurements of transpiration from cotton grown under ambient and enriched CO2 concentrations, Agric. For. Meteorol., 70(1-4), 231-245, doi:10.1016/0168-1923(94)90060-4, 1994.

445 Ellsäßer, F., Röll, A., Ahongshangbam, J., Waite, P. A., Hendrayanto, Schuldt, B. and Hölscher, D.: Predicting tree sap flux and stomatal conductance from drone-recorded surface temperatures in a mixed agroforestry system-a machine learning approach, Remote Sens., 12(24), 1-20, doi:10.3390/rs12244070, 2020.

Ewers, B. E. and Oren, R.: Analyses of assumptions and errors in the calculation of stomatal conductance from sap flux measurements, Tree Physiol., 20(9), 579-589, doi:10.1093/treephys/20.9.579, 2000.

450 Fan, J., Zheng, J., Wu, L. and Zhang, F.: Estimation of daily maize transpiration using support vector machines, extreme gradient boosting, artificial and deep neural networks models, Agric. Water Manag., 245, 106547, doi:10.1016/j.agwat.2020.106547, 2021.

Fassnacht, F. E., Latifi, H., Stereńczak, K., Modzelewska, A., Lefsky, M., Waser, L. T., Straub, C. and Ghosh, A.: Review of studies on tree species classification from remotely sensed data, Remote Sens. Environ., 186, 64-87, doi:10.1016/j.rse.2016.08.013, 2016.

Gebauer, T., Horna, V. and Leuschner, C.: Variability in radial sap flux density patterns and sapwood area among seven cooccurring temperate broad-leaved tree species, Tree Physiol., 28(12), 1821-1830, doi:10.1093/treephys/28.12.1821, 2008.

Gharari, S., Gupta, H. V., Clark, M. P., Hrachowitz, M., Fenicia, F., Matgen, P. and Savenije, H. H. G.: Understanding the Information Content in the Hierarchy of Model Development Decisions: Learning From Data, Water Resour. Res., 57(6), 
doi:10.1029/2020WR027948, 2021.

Granier, A. and Loustau, D.: Measuring and modelling the transpiration of a maritime pine canopy from sap-flow data, Agric. For. Meteorol., 71(1-2), 61-81, doi:10.1016/0168-1923(94)90100-7, 1994.

Gupta, H. V., Bastidas, L. A., Sorooshian, S., Shuttleworth, W. J. and Yang, Z. L.: Parameter estimation of a land surface scheme using multicriteria methods, J. Geophys. Res. Atmos., 104(D16), 19491-19503, doi:10.1029/1999JD900154, 1999.

Hassler, S. K., Weiler, M. and Blume, T.: Tree-, stand- and site-specific controls on landscape-scale patterns of transpiration, Hydrol. Earth Syst. Sci., 22(1), 13-30, doi:10.5194/hess-22-13-2018, 2018.

Hissler, C., Martínez-Carreras, N., Barnich, F., Gourdol, L., Iffly, J. F., Juilleret, J., Klaus, J. and Pfister, L.: The Weierbach experimental catchment in Luxembourg: A decade of critical zone monitoring in a temperate forest - from hydrological investigations to ecohydrological perspectives, Hydrol. Process., 35(5), 1-7, doi:10.1002/hyp.14140, 2021.

Hoek van Dijke, A. J., Mallick, K., Teuling, A. J., Schlerf, M., Machwitz, M., Hassler, S. K., Blume, T. and Herold, M.: Does the Normalized Difference Vegetation Index explain spatial and temporal variability in sap velocity in temperate forest ecosystems?, Hydrol. Earth Syst. Sci., 23(4), 2077-2091, doi:10.5194/hess-23-2077-2019, 2019.

Hrachowitz, M., Stockinger, M., Coenders-Gerrits, M., van der Ent, R., Bogena, H., Lücke, A. and Stumpp, C.: Reduction of vegetation-accessible water storage capacity after deforestation affects catchment travel time distributions and increases young water fractions in a headwater catchment, Hydrol. Earth Syst. Sci., 25(9), 4887-4915, doi:10.5194/hess-25-4887-2021, 2021. Jackisch, C.: Linking structure and functioning of hydrological systems., KIT - Karlsruher Institut of Technology., 2015. Jarvis, P. G.: The Interpretation of the Variations in Leaf Water Potential and Stomatal Conductance Found in Canopies in the Field, Philos. Trans. R. Soc. B Biol. Sci., 273(927), 593-610, doi:10.1098/rstb.1976.0035, 1976.

Köstner, B. M. M., Schulze, E. D., Kelliher, F. M., Hollinger, D. Y., Byers, J. N., Hunt, J. E., McSeveny, T. M., Meserth, R. and Weir, P. L.: Transpiration and canopy conductance in a pristine broad-leaved forest of Nothofagus: an analysis of xylem sap flow and eddy correlation measurements, Oecologia, 91(3), 350-359, doi:10.1007/BF00317623, 1992.

Loritz, R., Hassler, S. K., Jackisch, C., Allroggen, N., van Schaik, L., Wienhöfer, J. and Zehe, E.: Picturing and modeling catchments by representative hillslopes, Hydrol. Earth Syst. Sci., 21(2), 1225-1249, doi:10.5194/hess-21-1225-2017, 2017.

Loritz, R., Kleidon, A., Jackisch, C., Westhoff, M., Ehret, U., Gupta, H. and Zehe, E.: A topographic index explaining 485 hydrological similarity by accounting for the joint controls of runoff formation, Hydrol. Earth Syst. Sci., 23(9), 3807-3821, doi:10.5194/hess-23-3807-2019, 2019.

Loritz, R., Hrachowitz, M., Neuper, M. and Zehe, E.: The role and value of distributed precipitation data in hydrological models, Hydrol. Earth Syst. Sci., 25(1), 147-167, doi:10.5194/hess-25-147-2021, 2021.

Mencuccini, M., Manzoni, S. and Christoffersen, B.: Modelling water fluxes in plants: from tissues to biosphere, New Phytol., 490 222(3), 1207-1222, doi:10.1111/nph.15681, 2019.

Mendoza, P. A., Clark, M. P., Barlage, M., Rajagopalan, B., Samaniego, L., Abramowitz, G. and Gupta, H.: Are we unnecessarily constraining the agility of complex process-based models?, Water Resour. Res., 51(1), 716-728, doi:10.1002/2014WR015820, 2015. 
Monteith, J. L. and Unsworth, M. H.: Principles of Environmental Physics, Fourth Edi., Elsevier., 2013. water flux partitioning, water ages and hydrological connectivity: Insights from tracer-aided ecohydrological modelling, Hydrol. Earth Syst. Sci., 25(9), 4861-4886, doi:10.5194/hess-25-4861-2021, 2021.

Pfister, L., Iffly, J.-F., Hoffmann, L. and Humbert, J.: Use of regionalized stormflow coefficients with a view to hydroclimatological hazard mapping, Hydrol. Sci. J., 47(3), 479-491, doi:10.1080/02626660209492948, 2002.

Pfister, L., Martínez-Carreras, N., Hissler, C., Klaus, J., Carrer, G. E., Stewart, M. K. and McDonnell, J. J.: Recent Trends in Rainfall-Runoff Characteristics in the Alzette River Basin, Luxembourg, Hydrol. Process., 31(10), 1828-1845, doi:10.1023/A:1005567808533, 2017.

Phillips, N. and Oren, R.: A comparison of daily representations of canopy conductance based on two conditional timeaveraging methods and the dependence of daily conductance on environmental factors, Ann. des Sci. For., 55(1-2), 217-235, doi:10.1051/forest:19980113, 1998.

Poyatos, R., Granda, V., Molowny-Horas, R., Mencuccini, M., Steppe, K. and Martínez-Vilalta, J.: SAPFLUXNET: Towards a global database of sap flow measurements, Tree Physiol., 36(12), 1449-1455, doi:10.1093/treephys/tpw110, 2016.

Reichstein, M., Camps-Valls, G., Stevens, B., Jung, M., Denzler, J., Carvalhais, N. and Prabhat: Deep learning and process understanding for data-driven Earth system science, Nature, 566(7743), 195-204, doi:10.1038/s41586-019-0912-1, 2019.

Saunders, A., Drew, D. M. and Brink, W.: Machine learning models perform better than traditional empirical models for stomatal conductance when applied to multiple tree species across different forest biomes, Trees, For. People, 6, 100139, doi:10.1016/j.tfp.2021.100139, 2021.

Seibert, S. P., Jackisch, C., Ehret, U., Pfister, L. and Zehe, E.: Unravelling abiotic and biotic controls on the seasonal water balance using data-driven dimensionless diagnostics, Hydrol. Earth Syst. Sci., 21(6), 2817-2841, doi:10.5194/hess-21-2817-

$5152017,2017$.

Stewart, J. : Modelling surface conductance of pine forest, Agric. For. Meteorol., 43(1), 19-35, doi:10.1016/01681923(88)90003-2, 1988.

Stoy, P. C., El-Madany, T. S., Fisher, J. B., Gentine, P., Gerken, T., Good, S. P., Klosterhalfen, A., Liu, S., Miralles, D. G., Perez-Priego, O., Rigden, A. J., Skaggs, T. H., Wohlfahrt, G., Anderson, R. G., Coenders-Gerrits, A. M. J., Jung, M., Maes,

520 W. H., Mammarella, I., Mauder, M., Migliavacca, M., Nelson, J. A., Poyatos, R., Reichstein, M., Scott, R. L. and Wolf, S.: Reviews and syntheses: Turning the challenges of partitioning ecosystem evaporation and transpiration into opportunities, Biogeosciences, 16(19), 3747-3775, doi:10.5194/bg-16-3747-2019, 2019.

Su, Y., Shao, W., Vlček, L. and Langhammer, J.: Ecohydrological behaviour of mountain beech forest: Quantification of stomatal conductance using sap flow measurements, Geosci., 9(5), doi:10.3390/geosciences9050243, 2019.

525 Tyree, M. T. and Ewers, F. W.: The hydraulic architecture of trees and other woody plants, New Phytol., 119(3), 345-360, doi:10.1111/j.1469-8137.1991.tb00035.x, 1991.

Wienhöfer, J. and Zehe, E.: Predicting subsurface stormflow response of a forested hillslope - the role of connected flow paths, 
Hydrol. Earth Syst. Sci., 18(1), 121-138, doi:10.5194/hess-18-121-2014, 2014.

Wienhöfer, J., Lindenmaier, F. and Zehe, E.: Temporal variability of a slow-moving landslide: the Heumöser Hang case study in Vorarlberg, Austria, Landslide Process. - From Geomorphol. Mapp. to Dyn. Model., 221-225, 2009.

Zehe, E., Ehret, U., Pfister, L., Blume, T., Schröder, B., Westhoff, M., Jackisch, C., Schymanski, S. J., Weiler, M., Schulz, K., Allroggen, N., Tronicke, J., van Schaik, L., Dietrich, P., Scherer, U., Eccard, J., Wulfmeyer, V. and Kleidon, A.: HESS Opinions: From response units to functional units: a thermodynamic reinterpretation of the HRU concept to link spatial organization and functioning of intermediate scale catchments, Hydrol. Earth Syst. Sci., 18(11), 4635-4655, doi:10.5194/hess535 18-4635-2014, 2014.

Zhang, J.-G., He, Q.-Y., Shi, W.-Y., Otsuki, K., Yamanaka, N. and Du, S.: Radial variations in xylem sap flow and their effect on whole-tree water use estimates, Hydrol. Process., 29(24), 4993-5002, doi:10.1002/hyp.10465, 2015.

Zhao, W. L., Gentine, P., Reichstein, M., Zhang, Y., Zhou, S., Wen, Y., Lin, C., Li, X. and Qiu, G. Y.: Physics-Constrained Machine Learning of Evapotranspiration, Geophys. Res. Lett., 46(24), 14496-14507, doi:10.1029/2019GL085291, 2019.

540 Zheng, J., Fan, J., Zhang, F., Wu, L., Zou, Y. and Zhuang, Q.: Estimation of rainfed maize transpiration under various mulching methods using modified Jarvis-Stewart model and hybrid support vector machine model with whale optimization algorithm, Agric. Water Manag., 249, 106799, doi:10.1016/j.agwat.2021.106799, 2021. 